\title{
Biosensor Based on Cysteine Monolayer and Monoclonal Antibody for Specific Detection of Aflatoxin $B_{1}$ in Rice
}

\author{
Estéfani P. Simão, ${ }^{a}$ Gilcelia J. L. S. Barbieri, ${ }^{b}$ Cesar A. S. Andrade ${ }^{a, b}$ and \\ Maria D. L. Oliveira ${ }^{*, a}$
}

\begin{abstract}
${ }^{a}$ Departamento de Bioquímica and ${ }^{b}$ Programa de Pós-Graduação em Inovação Terapêutica, Universidade Federal de Pernambuco, 50670-901 Recife-PE, Brazil
\end{abstract}

\begin{abstract}
An electrochemical immunosensor for detection of aflatoxin $\mathrm{B}_{1}\left(\mathrm{AFB}_{1}\right)$ in food samples was developed. The sensor is composed by cysteine monolayer immobilized on gold electrode surface with subsequent bind to monoclonal antibody (MAb-Cys-modified electrode). The $\mathrm{AFB}_{1}$ detection was evaluated by cyclic voltammetry and impedance spectroscopy in the frequency range of $100 \mathrm{mHz}-100 \mathrm{kHz}$. Samples of rice were spiked with $\mathrm{AFB}_{1}$ to evaluate the sensitivity of the sensor. Impedance spectra could be fitted to a Randles equivalent circuit containing a constant phase element. Atomic force microscope (AFM) images showed MAb-AFB ${ }_{1}$ complex immobilized across the electrode surface. The electron transfer resistance $\left(R_{c t}\right)$ increase was attributed to a decrease in the charge permeability of the $M A b-A_{1}-A u$ surface to a redox probe $\mathrm{K}_{4}\left[\mathrm{Fe}(\mathrm{CN})_{6}\right]^{4-} / \mathrm{K}_{3}\left[\mathrm{Fe}(\mathrm{CN})_{6}\right]^{3-}$. The surface coverage exhibited a linear relationship as function of toxin concentration and is found to be 0.75 at $30 \mu \mathrm{gL}^{-1}$. The obtained sensor is a promising candidate for detection of $\mathrm{AFB}_{1}$ in rice with sensitivity and specificity.
\end{abstract}

Keywords: biosensor, impedance, cyclic voltammetry, aflatoxin

\section{Introduction}

Toxins are substances produced by plants, animals and microorganisms that cause adverse effects in human being. Also, toxins are a serious problem for food industry and affect the economy of many countries by interfering with production and exportation of foods. ${ }^{1,2}$ Mycotoxins are toxic compounds synthesized by fungi and easily found throughout the food chain and causing harm to human health. ${ }^{3}$

Aflatoxin $\mathrm{B}_{1}\left(\mathrm{AFB}_{1}\right)$ is a secondary metabolite produced mainly by fungus Aspergillus flavus and Aspergillus parasiticus with capability to colonize food and feed during harvesting, storage and processing. ${ }^{4} \mathrm{AFB}_{1}$ is considered the most toxic of all aflatoxins due to the carcinogenic, teratogenic, mutagenic and immunosuppressive properties. ${ }^{5}$ European legislation establishes $2 \mathrm{mg} \mathrm{kg}^{-1}$ as the maximum amount of $\mathrm{AFB}_{1}$ in food, which above of this level toxic manifestations may arise, leading to liver cancer. ${ }^{6}$ Therefore, a previous identification of the contaminated samples is important to ensure quality and safety in the food chain.

*e-mail: m_danielly@yahoo.com.br
Diverse methods, such as liquid chromatographymass spectrometry (LC-MS), liquid chromatographytandem mass spectrometry (LC-MS/MS), enzyme-linked immunosorbent assay (ELISA), thin-layer chromatography (TLC) and high-performance liquid chromatography (HPLC), have been used in order to identify $\mathrm{AFB}_{1}$ in diverse samples..$^{7-12}$ In spite of these methods have high sensitivity and specificity, they are time-consuming, require experienced technicians, extensive sample pre-treatment and, in some cases, are expensive equipments. ${ }^{13,14}$ Thus, there is an urgent need for the development of new sensor strategies applied for $\mathrm{AFB}_{1}$ screening in food industry and inspection agencies. Immunosensors represent an alternative as a screening tool due to the specificity, sensitivity and in-field detection of $\mathrm{AFB}_{1}$ in foodstuffs. ${ }^{15}$

In recent years, electrochemical immunosensors have been developed for specific detection of toxic small molecules using monoclonal antibodies (MAbs). ${ }^{16-18}$ In addition, cyclic voltammetry (CV) and electrochemical impedance spectroscopy (EIS) are useful techniques for the development of immunosensors due to their high sensitivity, low cost and possibility of instrument miniaturization. ${ }^{19}$ EIS is based on the application of a small alternating current (AC) potential as a function of time to measure the current 
generated. CV technique is used to acquire qualitative information about electrochemical processes relating the magnitude of the current generated by electron transfer during the redox process with the amount of analyte present in the electrode-solution interface. ${ }^{20,21}$

Self-assembled monolayers (SAM) have been used to obtain a well-ordered ultrathin layer to the development of bio-devices with high sensitivity and reproducibility. ${ }^{22,23}$ In this study, we modified the bare gold electrode (BGE) surface with a SAM of cysteine (Cys), an amino acid formed by three functional groups $\left(-\mathrm{SH},-\mathrm{COOH}\right.$ and $\left.-\mathrm{NH}_{2}\right)$ in its structure. ${ }^{24}$ Subsequently, SAM of Cys were chemically activated using 1-[3-(dimethylamino)propyl]-3-ethylcarbodiimide hydrochloride (EDC) and $N$-hydroxysuccinimide (NHS) for antibody immobilization. The fabrication process of the biosensor is shown in Figure 1. Atomic force microscopy (AFM), CV and EIS techniques were used to study the process of the electrode modification and detection of $\mathrm{AFB}_{1}$ in samples of rice contaminated with $\mathrm{AFB}_{1}$.

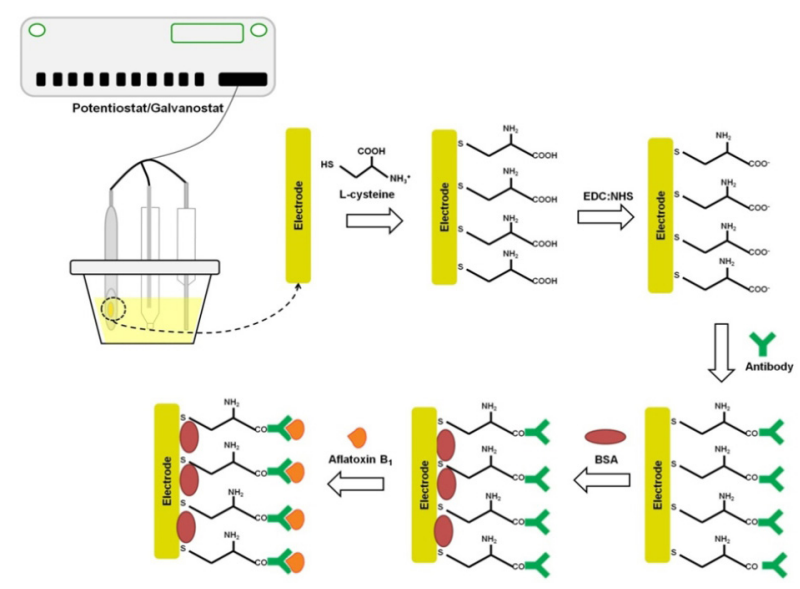

Figure 1. Schematic representation of the immunosensor fabrication. Steps of electrode modification consisting in cysteine (Cys) adsorption, $\mathrm{COOH}$ activation, antibody immobilization, remaining biding sites blockage by bovine serum albumin (BSA) and sample evaluation.

\section{Experimental}

Materials

Bovine serum albumin (BSA), L-cysteine, $\mathrm{AFB}_{1}$ and anti- $\mathrm{AFB}_{1}$ rabbit monoclonal antibody $\left(\mathrm{MAb}-\mathrm{AFB}_{1}\right)$, 1-[3-(dimethylamino)propyl]-3-ethylcarbodiimide hydrochloride (EDC) and N-hydroxysuccinimide (NHS) were purchased from Sigma-Aldrich (St. Louis, MO, USA). Potassium ferri- and ferrocyanide were obtained from Vetec (Rio de Janeiro, RJ, Brazil). All chemicals and solvents were of analytical-grade and used as received, without further purification. High-purity water was obtained after a Milli-Q plus treatment (Millipore, Billerica, MA, USA).

\section{Preparation of the biosensor system}

Initially, BGE was cleaned using piranha solution rinsed thoroughly with ultrapure water, and dried at room temperature (r.t.). SAM formation was preceded by adding a small volume of Cys $(1 \mu \mathrm{L}, 25 \mathrm{mM})$ diluted in phosphate buffer (PB) on BGE surface and allowed to dry for $10 \mathrm{~min}$. Then, the electrode was washed with PB to remove any unbound Cys molecules. Subsequently, $1 \mu \mathrm{L}$ of $0.4 \mathrm{~mol} \mathrm{~L}^{-1}$ EDC and $0.1 \mathrm{~mol} \mathrm{~L}^{-1} \mathrm{NHS}$ at a ratio of 1:1 (v/v) was dropwise on the Cys-modified BGE surface and waiting for $10 \mathrm{~min}$. After that, $1 \mu \mathrm{L}$ of MAb-AFB 1 solution $\left(25 \mathrm{mg} \mathrm{mL}^{-1}\right)$ was dropped on the Cys-EDC-NHS-modifiedBGE surface and incubated for $10 \mathrm{~min}$ at r.t.; in order to block the remaining active sites, it was added $1 \mu \mathrm{L} \mathrm{BSA}(10 \%, \mathrm{~m} / \mathrm{v})$ to the BGE surface for $10 \mathrm{~min}$.

\section{Sample preparation}

Uncontaminated rice used in this study was obtained from a local market. Initially, the rice was ground in a household blender. Subsequently, $1 \mathrm{mg}$ of ground rice sample was spiked with $\mathrm{AFB}_{1}\left(150 \mathrm{mg} \mathrm{mL}^{-1}\right)$ and mixed in a vortex mixer. After that, $5 \mathrm{~mL}$ of methanol $(80 \%, \mathrm{v} / \mathrm{v})$ was added to the sample, followed by shaking during $45 \mathrm{~min}$ and centrifuged at $5000 \mathrm{rpm}$ for $10 \mathrm{~min}$. The supernatant was carefully removed and diluted in PB to obtain different concentrations of $\mathrm{AFB}_{1}\left(0.5\right.$ and $1 \mathrm{ng} \mathrm{mL} \mathrm{m}^{-1} ; 1,5,10,20$ and $\left.30 \mathrm{mg} \mathrm{mL}^{-1}\right) .{ }^{16}$

\section{Biorecognition experiments}

The experiments of biorecognition were carried out by the addition of $1 \mu \mathrm{L} \mathrm{AFB}_{1}$ at different concentrations ( 0.5 and $1 \mathrm{ng} \mathrm{mL}^{-1} ; 1,5,10,20$ and $30 \mathrm{mg} \mathrm{mL}^{-1}$ ) on the sensor surface for $10 \mathrm{~min}$. Finally, experiments using samples of rice containing different concentrations of $\mathrm{AFB}_{1}$ were performed.

\section{Electrochemical measurements}

Electrochemical measurements were carried out on a PGSTAT $128 \mathrm{~N}$ potentiostat/galvanostat (Metrohm Autolab B.V., Utrecht, The Netherlands). An electrochemical cell containing three electrodes, platinum wire as auxiliary electrode, $\mathrm{Ag} / \mathrm{AgCl}$ (saturated with $\mathrm{KCl}$ ) electrode as reference electrode, and gold disk electrode as working electrode was used. The analysis were performed in the presence of a $10 \mathrm{mmol} \mathrm{L}^{-1} \mathrm{~K}_{4}\left[\mathrm{Fe}(\mathrm{CN})_{6}\right]^{4-} / \mathrm{K}_{3}\left[\mathrm{Fe}(\mathrm{CN})_{6}\right]^{3-}(1: 1)$ redox pair solution in $10 \mathrm{mmol} \mathrm{L}^{-1} \mathrm{~PB}$ (pH 7.4). Nyquist plots were obtained in a frequency range varying between 
$100 \mathrm{mHz}$ to $100 \mathrm{kHz}$ with amplitude of the applied sine wave potential of $10 \mathrm{mV}$ and $\mathrm{CV}$ plots were obtained at a potential range between -0.2 and $+0.7 \mathrm{~V}$ in a scan rate of $50 \mathrm{mV} \mathrm{s}^{-1}$.

\section{Atomic force microscopy analysis}

Atomic force microscopy measurements were performed using a PicoSPM II microscope (Molecular Imaging, Tempe, AZ, USA). Cantilevers with a silicon AFM probe (Multi $75 \mathrm{Al}$, resonant frequency $=75 \mathrm{KHz}$, force constant $=3 \mathrm{~N} \mathrm{~m}^{-1}$ ) were used for the noncontact mode AFM in air at r.t. (ca. $25^{\circ} \mathrm{C}$ ). Lateral resolution was set at $512 \times 512$ pixels in a scan area of $5 \times 5 \mu \mathrm{m}$. Images were obtained from at least three macroscopically separated areas to ensure a good distribution and analyzed using AFM Gwyddion software. ${ }^{25}$

\section{Results and Discussion}

\section{Morphological characterization}

The topographical and morphological analyses were performed by means of AFM. Atomic force microscopy is an excellent complementary technique to evaluate biosensors, since the electrochemical response depends on the morphology, such as surface roughness, porosity of films and defects. ${ }^{26}$ Typical topographical (2D) and 3D AFM images of the substrates surfaces containing Cys, Cys-MAb and Cys-MAb-AFB ${ }_{1}$ obtained by contact mode are shown in Figure 2. Figure 2a shows the topography of the electrode surface after Cys modification. Our results for Cys height are in accordance with a previous work. ${ }^{27}$ Of note, it can be seen a complete and homogeneous layer of the surface without the presence of aggregates or defects. After obtaining the Cys-MAb sensor system, it is visualized an increase in the surface roughness (Figure $2 b$ ). Cys-MAb sensor system shows a surface roughness of $24 \pm 2 \mathrm{~nm}$. Immobilized MAb has a more globular looking (Figure 2c), demonstrating its protein nature. ${ }^{28}$ Some authors found a typical height for antibody layer ranging from 6 to $12 \mathrm{~nm} \cdot{ }^{28,29}$ When comparing the AFM images of the sensor system before and after $\mathrm{AFB}_{1}$ recognition, an obvious difference could be observed, indicating that the $\mathrm{AFB}_{1}$ was successfully recognized.

\section{Electrochemical characterization of the immunosensor}

A previous study varying the concentration of Cys $\left(10,15,20,25\right.$ and $\left.30 \mathrm{mmol} \mathrm{L}^{-1}\right)$ was performed aiming to determine its optimal concentration for electrode modification (data not shown). At a fixed adsorption time
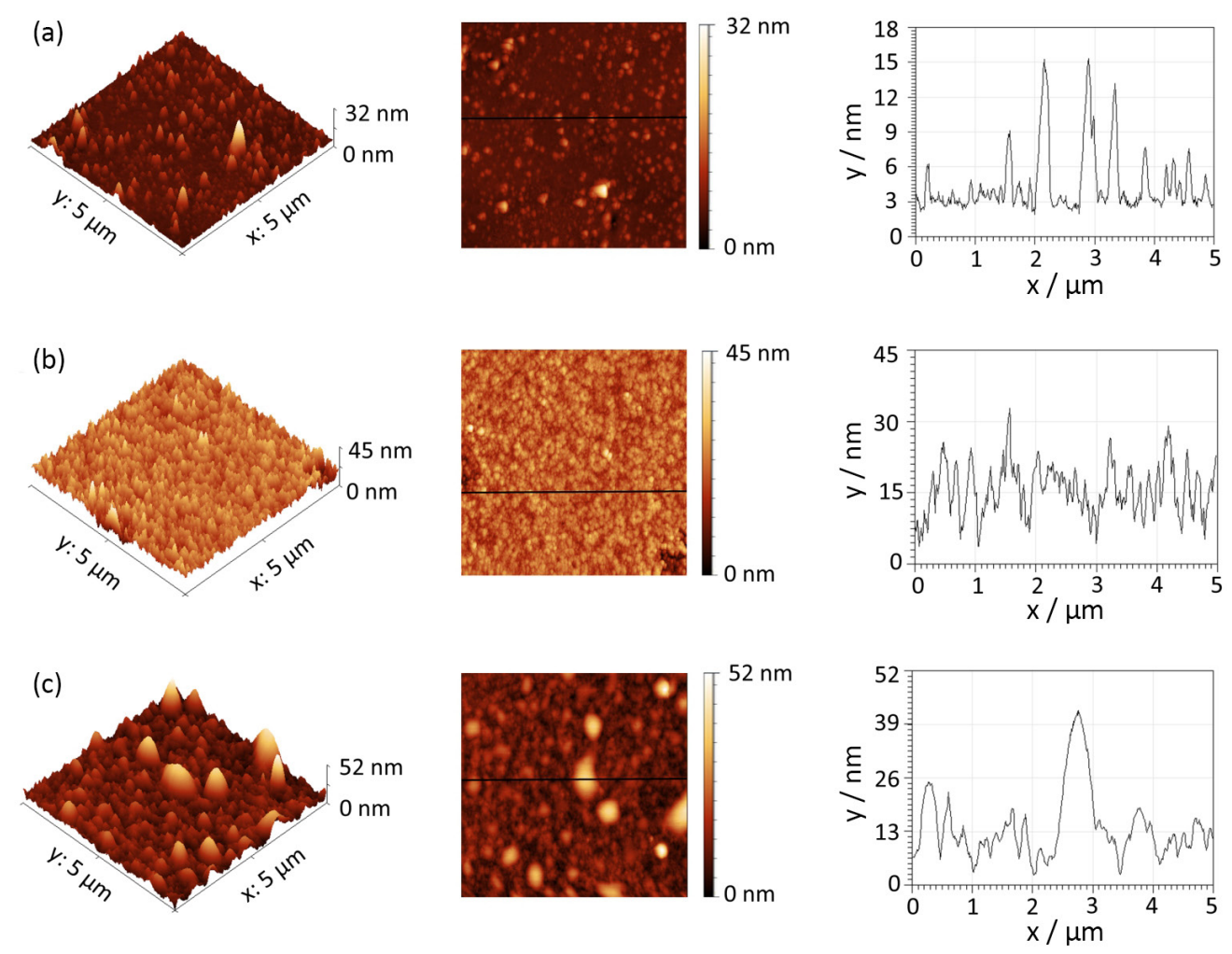

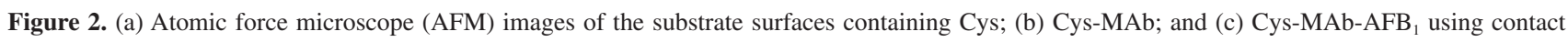
mode. Scan area of $5 \times 5 \mu \mathrm{m}$. 
(10 min), it was observed that after $25 \mathrm{mmol} \mathrm{L}^{-1}$ of Cys, the electrode surface saturation occurred. In addition, we performed a study varying the $\mathrm{MAb}-\mathrm{AFB}_{1}$ concentration $\left(18,25,50\right.$ and $\left.75 \mathrm{mg} \mathrm{mL}^{-1}\right)$ adsorbed on the electrode surface using an incubation time of $10 \mathrm{~min}$. We observed a saturation behavior of the electrode surface at $25 \mathrm{mg} \mathrm{mL}^{-1}$ of MAb-AFB ${ }_{1}$.

The coefficients of variation of the stepwise assembly immunosensor are shown in Figure 3a. The redox reaction of $\mathrm{K}_{4}\left[\mathrm{Fe}(\mathrm{CN})_{6}\right]^{4-} / \mathrm{K}_{3}\left[\mathrm{Fe}(\mathrm{CN})_{6}\right]^{3-}$ exhibits a reversible CVs for BGE. Cys is used to modify the electrode surface through a sulfhydryl group. The adsorption of the Cys on the electrode surface promoted a reduction in peak currents. Cys molecule can increase the resistance due to electrostatic repulsion between the carboxylic group of the Cys and negative charges of the probe redox $\mathrm{Fe}(\mathrm{CN})_{6}{ }^{4-/ 3-} \cdot 30$ After the co-addition of NHS and EDC coupling agents, the activated negatively charged terminal carboxylic group of Cys was replaced by NHS ester on the electrode surface. Therefore, an increase of amperometric response was observed due to an electrostatic attraction. The neutrally/ positively charged NHS ester promoted the transfer of the negative redox probe to the electrode surface. ${ }^{31}$ EDC-NHS coupling agents are important to facilitate binding of the antibody to the sensor system. Then, MAb-AFB ${ }_{1}$ was added to the sensor system to form a sensing layer. The $\mathrm{MAb}-\mathrm{AFB}_{1}$ immobilization on the sensor system promotes a decrease in the anodic and cathodic peak current of $\mathrm{K}_{4}\left[\mathrm{Fe}(\mathrm{CN})_{6}\right]^{4-} / \mathrm{K}_{3}\left[\mathrm{Fe}(\mathrm{CN})_{6}\right]^{3-}$. Subsequently, $10 \%$ BSA was added to block any nonspecific response, increasing the specificity of the sensor. ${ }^{14}$

Figure $3 b$ shows the Nyquist diagram corresponding to the modification of the BGE for obtaining the sensor electrode layer. The curve obtained for BGE reveals a small semicircle associated to a very low electron transfer resistance $\left(\mathrm{R}_{\mathrm{ct}}\right)$. The assemblage of Cys on the electrode surface induced an increase in the $\mathrm{R}_{\mathrm{ct}}$ as an indication of the electron transfer blockage. The modification of the Cys monolayer using EDC-NHS coupling agents resulted in a decrease of the $\mathrm{R}_{\mathrm{ct}}$. Coupling agents causes a decrease in resistance due to the attraction between the positively charged groups NHS and negative charge of the redox probe..$^{32} \mathrm{After}$ immobilization of the $\mathrm{MAb}-\mathrm{AFB}_{1}$ on Cys-modified electrode, it was obtained an increase in the $\mathrm{R}_{\mathrm{ct}}$. As expected, with the addition of BSA on MAb-AFB - -Cys-modified electrode, a new $R_{c t}$ increase was observed. The impedimetric response is increased after complete assembly of the system proportionally to the quantity of material immobilized on the electrode surface, demonstrating that the sensing layer was successfully obtained.
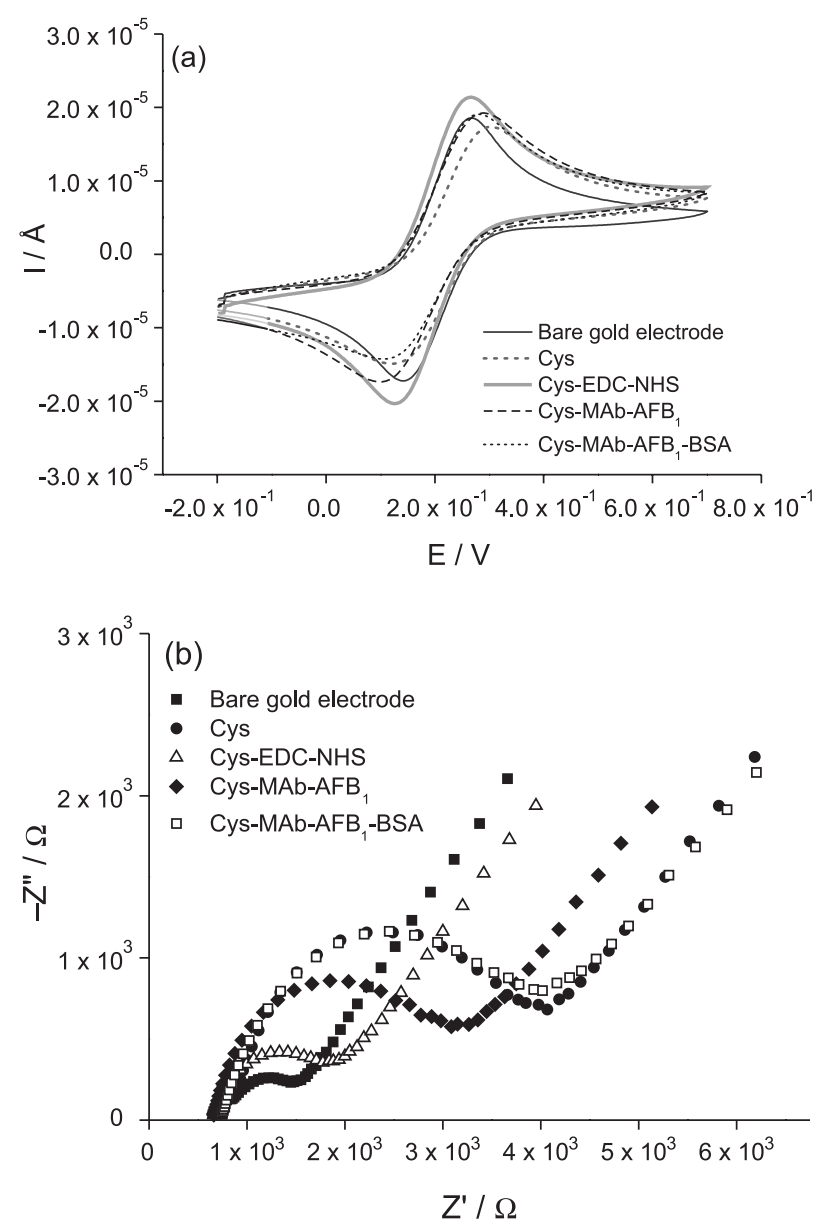

Figure 3. (a) Cyclic voltammograms and (b) Nyquist plots of the stepwise immobilization of Cys, Cys-EDC-NHS, Cys-MAb-AFB ${ }_{1}$ and Cys-MAb-AFB 1 -BSA. The impedance spectra were taken for $10 \mathrm{mM}$ $\mathrm{K}_{4}\left[\mathrm{Fe}(\mathrm{CN})_{6}\right]^{4-} / \mathrm{K}_{3}\left[\mathrm{Fe}(\mathrm{CN})_{6}\right]^{3-}(1: 1)$ in $10 \mathrm{mM}$ phosphate buffer (pH 7.4) in the frequency range from $100 \mathrm{mHz}$ to $100 \mathrm{kHz}$. All electrochemical measurements were performed in triplicate using three different samples.

\section{Aflatoxin $\mathrm{B}_{1}$ detection}

Figure $4 \mathrm{a}$ shows the biorecognition process of the immunosensor for five different concentrations of $\mathrm{AFB}_{1}$ (0.5 and $1 \mathrm{ng} \mathrm{mL} L^{-1} ; 1,5,10,20$ and $30 \mathrm{mg} \mathrm{mL}^{-1}$ ) and negative control. The CVs of different concentrations of $\mathrm{AFB}_{1}$ reveal a gradual decrease of the peak current and an increase in the peak-to-peak separation with increasing $\mathrm{AFB}_{1}$ concentration. The calibration curve is shown in Figure $4 \mathrm{~b}$. The curve exhibits a toxin detection ranging from $0.5 \mathrm{ng} \mathrm{mL}^{-1}$ to $30 \mathrm{mg} \mathrm{mL}^{-1}$. Based on this, we found that the calibration result is aligned with clinical reference range and can be applicable for identification of toxins in food. In addition, the coefficient of variation from this assay was found approximately within $2 \%$, supporting the applicability of this method for real field analysis.

To evaluate the specificity of the immunosensor, it was used a mycotoxin ochratoxin A as negative control. 
Viewing curve b (negative control) it is observed non-significant variations in the anodic and cathodic peaks of the voltammogram, demonstrating the specificity of the biosensor.

Figure $4 c$ shows a successive increase in the $R_{c t}$ values with increasing of $\mathrm{AFB}_{1}$ concentration. EIS results are in accordance with coefficient of variation analysis. The reduction of the amperometric response and gradual increase in the $\mathrm{R}_{\mathrm{ct}}$ values (Figures $4 \mathrm{a}, 4 \mathrm{~b}$ and $4 \mathrm{c}$, respectively) results from a progressive blockage of the electron passage in the electrode/solution interface. This blockage is related to the amount of the antibody-antigen complex $\left(\mathrm{MAb}-\mathrm{AFB}_{1}\right)$ formed on the electrode surface. In Figure $4 c$, we observed an insignificant $R_{c t}$ value due to the interaction of the immunosensor with negative control, demonstrating the specificity of the immunosensor.

Additionally, the Nyquist plots were submitted to analysis of data through EQUIVCRT program. ${ }^{33}$ The experimental data were fitted using a modified Randles equivalent circuit (insert of Figure 4c), which allowed to obtain theoretical curves (Figure 4c). Warburg impedance (W) represents the impedance of semi-infinite diffusion of the redox probe to the electrode. The ohmic resistance of the solution $\left(\mathrm{R}_{\Omega}\right)$ is associated with the bulk properties of the electrolyte solution. Constant-phase element $(\mathrm{Q})$ represents the behavior of a double layer for a non-homogeneous system. The phase angle of the Q element is related to $n$ parameter, where $n$ is related to the dispersion of relaxation time through the surface due to a non-homogeneity in the capacitance. ${ }^{34}$ Electron transfer resistance controls the electron transfer kinetics of the redox-probe at the electrode/electrolyte interface.

Table 1 shows the equivalent circuit parameters of the fitting curves for the immunosensor preparation followed by antibody interaction with different concentrations of $\mathrm{AFB}_{1}$ in samples.

The performance of the immunosensor for aflatoxin detection was evaluated through the relative variation of the $\mathrm{R}_{\mathrm{ct}}\left(\Delta \mathrm{R}_{\mathrm{ct}}\right)$, according to the equation 1 :

$\Delta \mathrm{R}_{\mathrm{ct}}=\left(\frac{\mathrm{R}_{\mathrm{ct}(\mathrm{toxin})}-\mathrm{R}_{\mathrm{ct}\left(\mathrm{MAb}-\mathrm{AFB}_{\mathrm{H}}\right)}}{\mathrm{R}_{\mathrm{ct}\left(\mathrm{MAb}-\mathrm{AFB} \mathrm{B}_{1}\right)}}\right) \times 100$

where $R_{c t(t o x i n)}$ is the value of the electron transfer resistance after recognition of the toxin and $\mathrm{R}_{\mathrm{ct}(\mathrm{MABA}-\mathrm{FB} 1)}$ corresponds to the $\mathrm{R}_{\mathrm{ct}}$ value of the sensor layer. $\Delta \mathrm{R}_{\mathrm{ct}}$ increases as function of toxin concentration (Figure 5a), indicating an interaction between antibody and $\mathrm{AFB}_{1}$. Thus, our results demonstrated that the modified electrode is effective on $\mathrm{AFB}_{1}$ detection. The filling of the recognition sites by toxin surface coverage $(\theta)$ can be calculated by (equation 2):
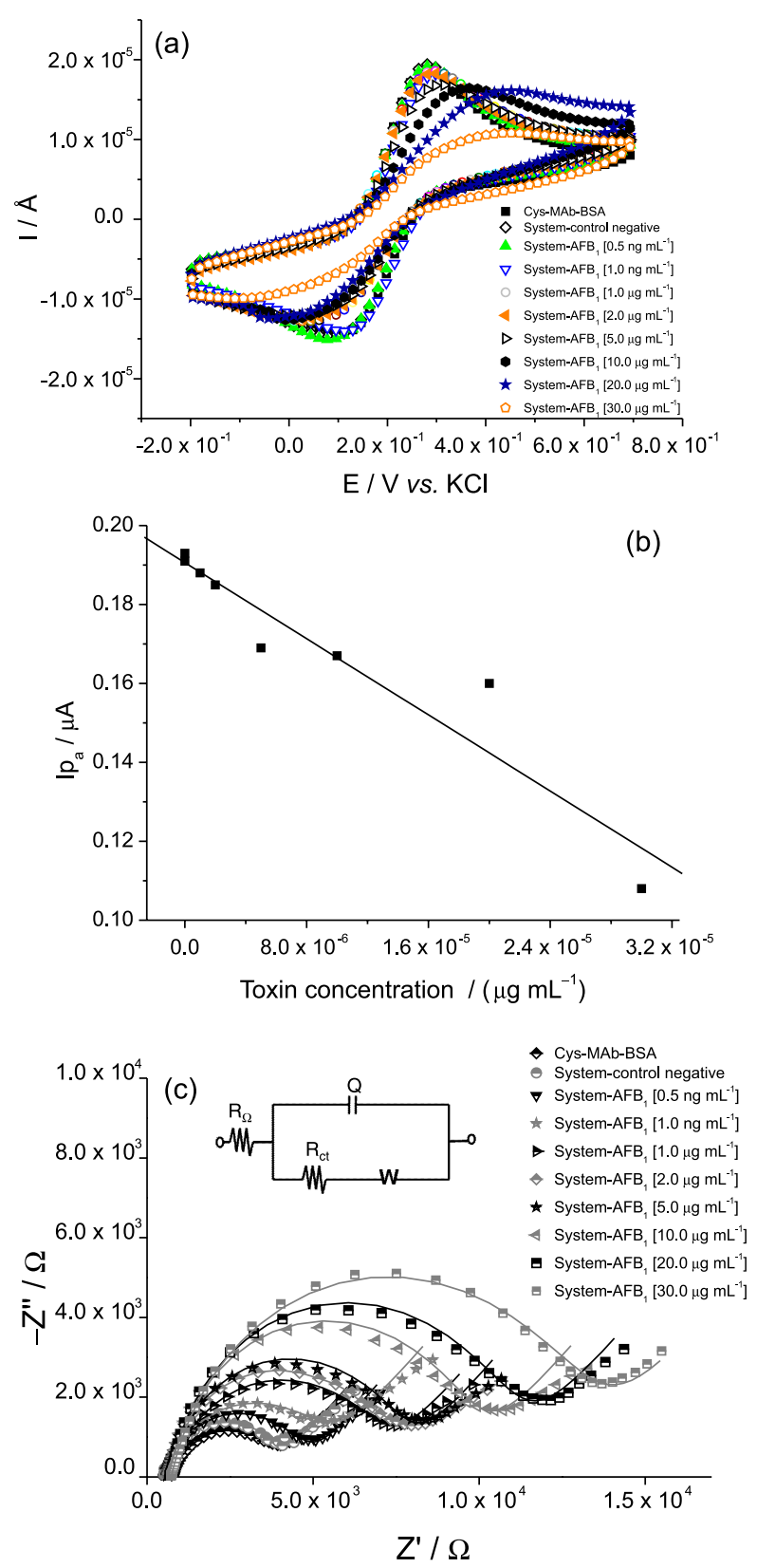

Figure 4. (a) Cyclic voltammograms; (b) calibration curve obtained from cyclic voltammetry (CV); and (c) Nyquist plots of the Cys-MAb-AFB - -BSA, system-control negative and system- $\mathrm{AFB}_{1}$ in the concentrations of 0.5 and $1 \mathrm{ng} \mathrm{mL}^{-1}, 1,2,5,10,20$ and $30 \mathrm{mg} \mathrm{mL}^{-1}$. Insert in (c) represents the equivalent circuit adopted to fit the impedance data, where $\mathrm{R}_{\Omega}$ is the ohmic resistance of the electrolyte solution, $\mathrm{Q}$ the phase constant element, $\mathrm{W}$ the Warburg impedance and $\mathrm{R}_{\mathrm{ct}}$ the electron-transfer resistance. Supporting electrolyte: $10 \mathrm{mM} \mathrm{K}_{4}\left[\mathrm{Fe}(\mathrm{CN})_{6}\right]^{4-} / \mathrm{K}_{3}\left[\mathrm{Fe}(\mathrm{CN})_{6}\right]^{3-}(1: 1)$ in phosphate buffer $10 \mathrm{mM}, \mathrm{pH} 7.4$ solution; scan rate of $50 \mathrm{mV} \mathrm{s}^{-1}$.

$\theta=1-\left(\frac{\mathrm{R}_{\mathrm{B}}}{\mathrm{R}_{\mathrm{C}}}\right)$

where $R_{B}$ is the charge transfer resistance for Cys-Mab-AFB biosystem and $R_{C}$ is the charge transfer resistance obtained for different concentrations of the $\mathrm{AFB}_{1}$ after interaction 
Table 1. Values of the equivalent circuit elements from fitted impedance results

\begin{tabular}{|c|c|c|c|}
\hline Modified electrode & $\mathrm{R}_{\mathrm{ct}}{ }^{\mathrm{a}} / \mathrm{k} \Omega$ & $\mathrm{Q}^{\mathrm{b}} / \mu \mathrm{F}$ & $\mathrm{n}^{\mathrm{c}}$ \\
\hline Bare gold electrode & 0.75 & 8.15 & 0.68 \\
\hline Cysteine & 2.99 & 3.34 & 0.81 \\
\hline Cysteine-EDC-NHS & 1.22 & 7.19 & 0.72 \\
\hline Cysteine-EDC-NHS-MAb & 2.40 & 3.78 & 0.77 \\
\hline Cysteine-EDC-NHS-MAb-BSA & 3.20 & 5.27 & 0.76 \\
\hline Cysteine-EDC-NHS-MAb-BSA-toxin $0.5 \mathrm{ng} \mathrm{mL}^{-1}$ & 4.20 & 2.78 & 0.80 \\
\hline Cysteine-EDC-NHS-MAb-BSA-toxin $1 \mathrm{ng} \mathrm{mL}{ }^{-1}$ & 4.74 & 4.30 & 0.80 \\
\hline Cysteine-EDC-NHS-MAb-BSA-toxin $1 \mathrm{mg} \mathrm{mL}^{-1}$ & 6.42 & 2.98 & 0.80 \\
\hline Cysteine-EDC-NHS-MAb-BSA-toxin $2 \mathrm{mg} \mathrm{mL}^{-1}$ & 6.75 & 1.69 & 0.86 \\
\hline Cysteine-EDC-NHS-MAb-BSA-toxin $5 \mathrm{mg} \mathrm{mL}^{-1}$ & 7.00 & 1.74 & 0.87 \\
\hline Cysteine-EDC-NHS-MAb-BSA-toxin $10 \mathrm{mg} \mathrm{mL}^{-1}$ & 8.99 & 1.41 & 0.89 \\
\hline Cysteine-EDC-NHS-MAb-BSA-toxin $20 \mathrm{mg} \mathrm{mL}^{-1}$ & 10.10 & 1.53 & 0.88 \\
\hline Cysteine-EDC-NHS-MAb-BSA-toxin $30 \mathrm{mg} \mathrm{mL}^{-1}$ & 12.40 & 3.03 & 0.84 \\
\hline Cysteine-EDC-NHS-MAb-BSA-rice $0.5 \mathrm{ng} \mathrm{mL}^{-1}$ & 3.70 & 3.50 & 0.85 \\
\hline Cysteine-EDC-NHS-MAb-BSA-rice $1 \mathrm{ng} \mathrm{mL}^{-1}$ & 4.04 & 3.91 & 0.83 \\
\hline Cysteine-EDC-NHS-MAb-BSA-rice $1 \mathrm{mg} \mathrm{mL}^{-1}$ & 5.06 & 7.50 & 0.76 \\
\hline Cysteine-EDC-NHS-MAb-BSA-rice $2 \mathrm{mg} \mathrm{mL}^{-1}$ & 6.21 & 5.12 & 0.80 \\
\hline Cysteine-EDC-NHS-MAb-BSA-rice $5 \mathrm{mg} \mathrm{mL} \mathrm{m}^{-1}$ & 6.76 & 4.00 & 0.83 \\
\hline Cysteine-EDC-NHS-MAb-BSA-rice $10 \mathrm{mg} \mathrm{mL}^{-1}$ & 9.81 & 4.88 & 0.81 \\
\hline Cysteine-EDC-NHS-MAb-BSA-rice $20 \mathrm{mg} \mathrm{mL}^{-1}$ & 10.84 & 4.60 & 0.81 \\
\hline Cysteine-EDC-NHS-MAb-BSA-rice $30 \mathrm{mg} \mathrm{mL}^{-1}$ & 14.70 & 3.87 & 0.82 \\
\hline
\end{tabular}

alectron transfer resistance; ${ }^{\mathrm{b}}$ constant-phase element; ${ }^{\mathrm{a}}$ related to the dispersion of relaxation time through the surface due to a non-homogeneity in the capacitance dispersion of relaxation time through the surface due to a non-homogeneity in the capacitance. EDC: 1-[3-(Dimethylamino)propyl]-3ethylcarbodiimide hydrochloride; NHS: $N$-hydroxysuccinimide; MAb: monoclonal antibody; BSA: bovine serum albumin.

with the immunosensor. Figure $5 \mathrm{~b}$ shows a plot of $\theta$ as a function of concentration of toxin linkage to the immunosensor. The values of $\theta$ exhibit a linear relationship with toxin concentration and is found to be $75 \%$ for $30 \mathrm{mg} \mathrm{mL}^{-1}$ of toxin.

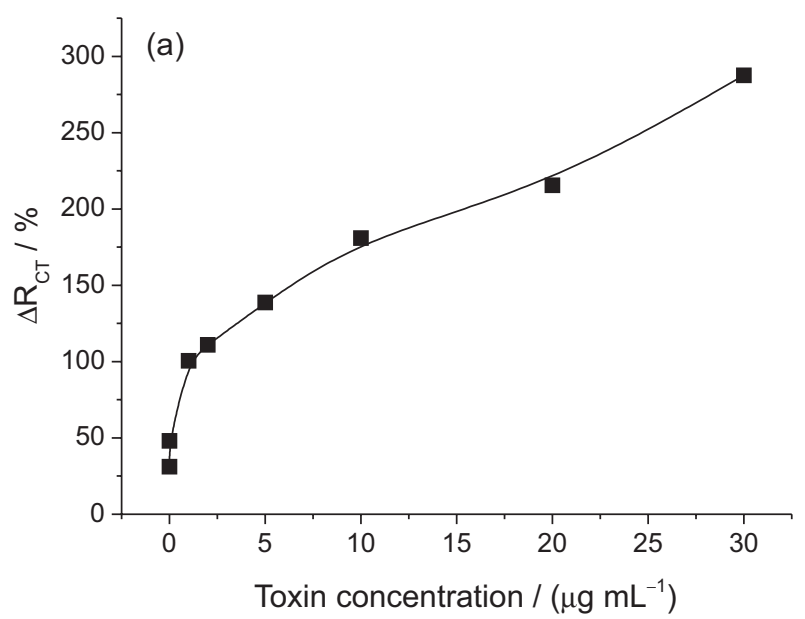

\section{Sample analysis}

After the initial analysis, the proposed immunosensor was applied to the determination of $\mathrm{AFB}_{1}$ in rice to test its performance in food samples. Figure 6 shows the

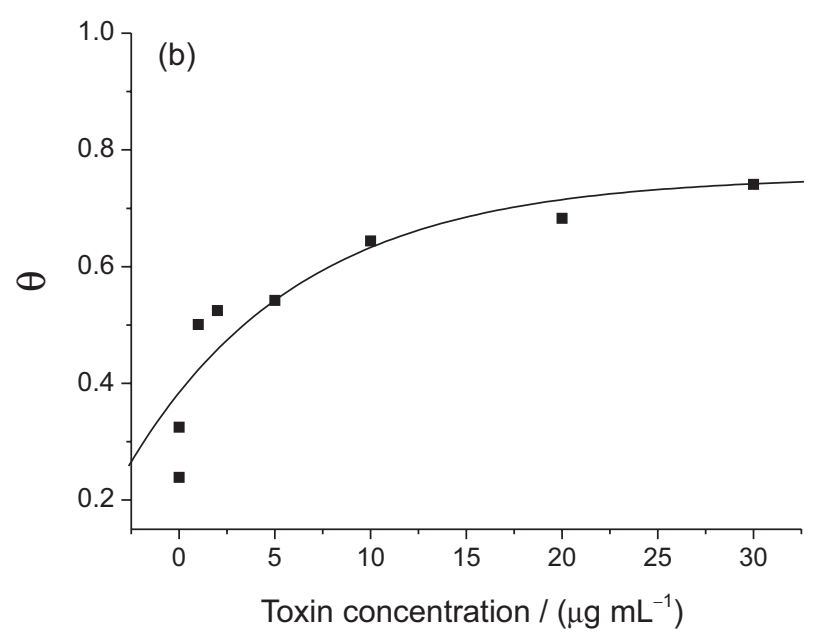

Figure 5. (a) Variation of electron transfer resistance $\left(\Delta R_{c t}\right)$; and (b) toxin surface coverage $(\theta)$ as a function of aflatoxin $B_{1}\left(A_{F B}\right)$ concentration. The experimental data used to calculate $\theta$ is shown in Table 1, including the standard deviation. All experiments were performed in triplicate using three different samples. 
electrochemical behavior of the immunosensor using samples. In Figure 6a, we showed the CVs of the biosystem at different concentrations of $\mathrm{AFB}_{1}$ in rice. After the assemblage of the system on the electrode surface and the process of linkage between the antibody and $\mathrm{AFB}_{1}$ present in rice, it is possible to observe a decrease in the peaks current of the redox probe followed by an increase in the peak-to-peak separation. A more detailed study of the sensitivity of the immunosensor was conducted by EIS. Distinct concentrations of $\mathrm{AFB}_{1}$ in rice were
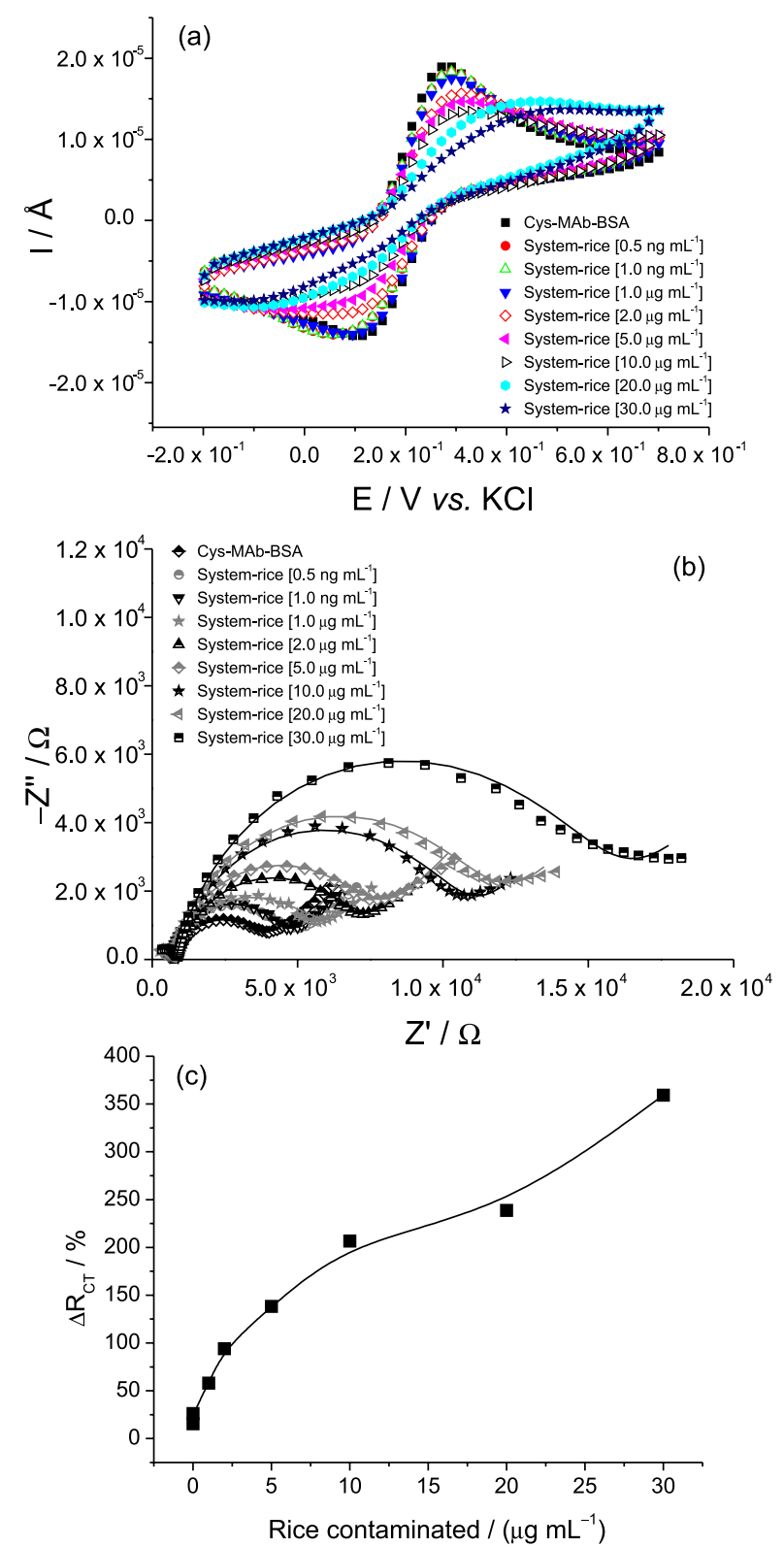

Figure 6. (a) Cyclic voltammograms; (b) Nyquist plots; and (c) variation of electron transfer resistance $\left(\Delta \mathrm{R}_{\mathrm{ct}}\right)$ of the immunosensor before and after interaction with aflatoxin $\mathrm{B}_{1}\left(\mathrm{AFB}_{1}\right)$ in rice at different concentrations. Cys-Mab-AFB ${ }_{1}$-BSA; system-control negative; and system- $\mathrm{AFB}_{1}$ at concentrations of 0.5 and $1 \mathrm{ng} \mathrm{mL}^{-1} ; 1,2,5,10,20$ and $30 \mathrm{mg} \mathrm{mL}^{-1}$. Supporting electrolyte: $10 \mathrm{mM} \mathrm{K}_{4}\left[\mathrm{Fe}(\mathrm{CN})_{6}\right]^{4-} / \mathrm{K}_{3}\left[\mathrm{Fe}(\mathrm{CN})_{6}\right]^{3-}(1: 1)$ in $10 \mathrm{mM}$ phosphate buffer (pH 7.4) solution; scan rate of $50 \mathrm{mV} \mathrm{s}^{-1}$. analyzed ( 0.5 and $1 \mathrm{ng} \mathrm{mL} L^{-1} ; 1,5,10,20$ and $\left.30 \mathrm{mg} \mathrm{mL}^{-1}\right)$ and the impedance spectra reveals an increase in the $R_{c t}$ proportional to $\mathrm{AFB}_{1}$ concentration (Figure 6b). At higher concentration, it can be observed an increased $R_{c t}$ value after recognition process of $\mathrm{AFB}_{1}$. In Figure $6 \mathrm{c}$ we observed a positive linear relationship between the $\Delta \mathrm{R}_{\mathrm{ct}}$ and $\mathrm{AFB}_{1}$ concentration available in contaminated rice. Therefore, our data indicates that the proposed sensor could detect $\mathrm{AFB}_{1}$ in spiked rice samples in small concentrations $\left(1 \mathrm{mg} \mathrm{mL}^{-1}\right)$, demonstrating that the established biosensing system could be applied for $\mathrm{AFB}_{1}$ determination in real agriculture products.

\section{Conclusions}

A highly selective label-free impedimetric immunosensor based on cysteine monolayer and monoclonal antibody for $\mathrm{AFB}_{1}$ detection in rice was obtained. Cyclic voltammetry and electrochemical impedance techniques were used to investigate the immobilization of MAb on cysteine layer. EDC-NHS system was usefull to immobilize MAb without lost in the protein function. The biorecognition process was revealed by the blockage of the charge transfer. Obtained results demonstrated a good filling of the recognition sites by toxin surface coverage. The resulting device exhibited good sensitivity and reproducibility and could be used to detect toxins in food.

\section{Acknowledgments}

The authors are grateful for support from the Rede de Nanobiotecnologia/CAPES, Instituto Nacional de Ciência e Tecnologia para Inovação Farmacêutica (INCT-IF), CNPq (grant No. 310305/2012-8 and 310361/2012-5) and FACEPE.

\section{References}

1. Leung, M. C. K.; Diaz-Llano, G.; Smith, T. K.; J. Agric. Food Chem. 2006, 54, 9623.

2. Bhat, R.; Rai, R. V.; Karim, A. A.; Compr. Rev. Food Sci. Food Saf. 2010, 9, 57.

3. Rai, M. K.; Bonde, S. R.; Ingle, A. P.; Gade, A. K.; J. Pharm. Educ. Res. 2012, 3, 22.

4. Ding, X. X.; Li, P. W.; Bai, Y. Z.; Zhou, H. Y.; Food Control 2012, 23, 143.

5. Awad, W. A.; Ghareeb, K.; Böhm, J.; J. Anim. Physiol. Anim. Nutr. 2010, 94, 486.

6. Anklam, E.; Stroka, J.; Boenke, A.; Food Control 2002, 13, 173.

7. Nonaka, Y.; Saito, K.; Hanioka, N.; Narimatsu, S.; Kataoka, H.; J. Chromatogr. A 2009, 1216, 4416. 
8. Bacaloni, A.; Cavaliere, C.; Cucci, F.; Foglia, P.; Samperi, R.; Lagana, A.; J. Chromatogr. A 2008, 1179, 182.

9. Li, P. W.; Zhang, Q.; Zhang, W.; TrAC, Trends Anal. Chem. 2009, 28, 1115.

10. Otta, K. H.; Papp, E.; Bagocsi, B.; J. Chromatogr. A 2000, 882, 11.

11. Fernandez, A.; Belio, R.; Ramos, J. J.; Sanz, M. C.; Saez, T.; J. Sci. Food Agric. 1997, 74, 161.

12. Jaimez, J.; Fente, C. A.; Vazquez, B. I.; Franco, C. M.; Cepeda, A.; Mahuzier, G.; Prognon, P.; J. Chromatogr. A 2000, $882,1$.

13. Stroka, J.; Anklam, E.; TrAC, Trends Anal. Chem. 2002, 21, 90.

14. Sharma, A.; Matharu, Z.; Sumana, G.; Solanki, P. R.; Kim, C. G.; Malhotra, B. D.; Thin Solid Films 2010, 519, 1213.

15. Ricci, F.; Volpe, G.; Micheli, L.; Palleschi, G.; Anal. Chim. Acta 2007, 605, 111.

16. Tan, Y.; Chu, X.; Shen, G. L.; Yu, R. Q.; Anal. Biochem. 2009, 387, 82.

17. Bacher, G.; Pal, S.; Kanungo, L.; Bhand, S.; Sens. Actuators, $B$ 2012, 168, 223.

18. Perrotta, P. R.; Arevalo, F. J.; Vettorazzi, N. R.; Non, M. A.; Fernandez, H.; Sens. Actuators, B 2012, 162, 327.

19. Ronkainen, N. J.; Halsall, H. B.; Heineman, W. R.; Chem. Soc. Rev. 2010, 39, 1747.

20. Brett, A. M. O.; Brett, C. M. A.; Eletrochemistry: Principles, Methods, and Applications; Oxford University Press: Oxford, 1993.
21. Bard, A. J.; Faulkner, L. R.; Electrochemical Methods: Fundamentals and Applications, $2^{\text {nd }}$ ed.; John Wiley \& Sons: Oxford, 2000.

22. Subramanian, A.; Irudayaraj, J.; Ryan, T.; Biosens. Bioelectron. 2006, 21, 998.

23. Arya, S. K.; Solanki, P. R.; Datta, M.; Malhotra, B. D.; Biosens. Bioelectron. 2009, 24, 2810.

24. Jiang, D.; Ji, J.; An, L.; Sun, X. L.; Zhang, Y.; Zhang, G.; Tang, L.; Biosens. Bioelectron. 2013, 50, 150.

25. Nečas, D.; Klapetek, P.; Cent. Eur. J. Phys. 2012, 10, 181.

26. Galal, A.; Atta, N. F.; El-Ads, E. H.; Talanta 2012, 93, 264.

27. Huayhuas-Chipana, B. C.; Gomero, J. C. M.; Sotomayor, M. D. P. T.; J. Braz. Chem. Soc. 2014, 25, 1737.

28. Yang, L. J.; Li, Y. B.; Biosens. Bioelectron. 2005, 20, 1407.

29. Hao, C.; Yan, F.; Ding, L.; Xue, Y. D.; Ju, H. X.; Electrochem. Commun. 2007, 9, 1359.

30. Luna, D. M. N.; Avelino, K. Y. P. S.; Cordeiro, M. T.; Andrade, C. A. S.; Oliveira, M. D. L.; Sens. Actuators, B 2015, 220, 565.

31. Geng, P.; Zhang, X.; Meng, W.; Wang, Q.; Zhang, W.; Jin, L.; Feng, Z.; Wu, Z.; Electrochim. Acta 2008, 53, 4663.

32. Ding, L.; Bond, A. M.; Zhai, J.; Zhang, J.; Anal. Chim. Acta 2013, 797, 1.

33. Boukamp, B. A.; Sol. St. Ionics 1996, 18, 136.

34. Silva, D. J. R.; Diniz, F. B.; Electrochim. Acta 2014, 119, 99.

Submitted: September 30, 2015 Published online: December 21, 2015 